\title{
Detection of the Genus Phytophthora and the Species Phytophthora nicotianae by LAMP with a QProbe
}

\author{
Ayaka Hieno, ${ }^{1, \dagger}$ Mingzhu Li, ${ }^{2}$ Auliana Afandi, ${ }^{3}$ Kayoko Otsubo, ${ }^{1}$ Haruhisa Suga, ${ }^{4}$ and Koji Kageyama ${ }^{1}$ \\ ${ }^{1}$ River Basin Research Center, Gifu University, 1-1 Yanagido, Gifu-city, Gifu, 501-1193, Japan \\ ${ }^{2}$ College of Life Sciences, Shaanxi Normal University, Xi' an, China \\ ${ }^{3}$ Biotechnology Research Center, Universitas Gadjah Mada, Yogyakarta, Indonesia \\ ${ }^{4}$ Life Science Research Center, Gifu University, 1-1 Yanagido, Gifu-city, Gifu, 501-1193, Japan
}

\begin{abstract}
Phytophthora is an oomycete genus with worldwide distribution, and many of its species cause destructive diseases. In Japan, Phytophthora species are listed as quarantine organisms with the exception of Phytophthora nicotianae. For effective quarantine control, we designed a Phytophthora genus-specific loop-mediated isothermal amplification (LAMP) primer set and a $P$. nicotianae species-specific quenching probe (QProbe) to establish a simultaneous LAMP-based detection method. We confirmed the specificity of the genus-specific primers,

fagopyri. These two species gave inconsistent results. We used annealing curve analysis with the QProbe to demonstrate that $P$. nicotianae could be distinguished from other species. DNA from inoculated and naturally infected plants was extracted using a time-saving extraction kit and subjected to the simultaneous detection method. We confirmed that all Phytophthora DNAs in the plant samples were detected, and $P$. nicotianae was specifically identified. This simultaneous detection method will make quarantine inspections faster and easier.
\end{abstract} and all 161 taxa were detected. No other species in the closely related genera Pythium and Phytopythium gave positive results with the exception of two species, Phytopythium delawarense and Phytopythium
Keywords: loop-mediated isothermal amplification, Phytophthora, Phytophthora nicotianae, oomycetes, pathogen detection, quenching probe
Most species in the oomycete genus Phytophthora are known as plant pathogens that cause serious commercial losses. An invasion of Phytophthora species in a new region will create unexpected threats to that region's ecosystems. Phytophthora infestans (Mont.) de Bary (de Bary 1876), which causes potato late blight, was responsible for the Irish potato famine in continental Europe in 1845-1849. More recently, the economic impact of the disease in the EU has been estimated at more than $€ 1$ billion per year (Haverkort et al. 2008). In the U.S.A., the costs of the disease are estimated at \$77.1 million in fungicides and \$210.7 million in lost revenue due to decreased yield, quality, and storability (Guenthner et al. 2001). Population genetic analyses based on microsatellite markers and nuclear gene sequences suggested that $P$. infestans was introduced to Europe from central Mexico in the 1840s (Goss et al. 2014).

Another destructive plant pathogen is Phytophthora ramorum Werres, de Cock \& Man in't Veld (Werres et al. 2001), which causes sudden oak death and has infected a range of forest and nursery trees in North America and Europe (Hansen 2015). The recent appearance of four lineages of $P$. ramorum (NA1, NA2, EU1, and EU2) is due to the independent introduction of NA1 and NA2 into North America and EU1 and EU2 into Europe (Goss et al. 2009; Van Poucke et al. 2012). A 2011 analysis of the EU1 linage obtained from nurseries in Europe and North America suggested that the linage had migrated from Europe to North America more commonly than in the other direction (Goss et al. 2011). The economic

${ }^{\dagger}$ Corresponding author: A. Hieno; hieno@green.gifu-u.ac.jp

Funding: This study was supported by a Grant-in Aid for "Development of detection and identification techniques for pests" in "Research and development of adaptation measures for global warming and abnormal weather" from the Ministry of Agriculture, Forestry, and Fisheries of Japan.

*The $\boldsymbol{e}$-Xtra logo stands for "electronic extra" and indicates that one supplementary table and three supplementary figures are published online.

The author(s) declare no conflict of interest.

Accepted for publication 11 March 2020.

(C) 2020 The American Phytopathological Society impacts of sudden oak death were estimated in the tens of millions of dollars in the U.S.A. (Grünwald et al. 2008), and in England and Wales, $£ 1.446$ billion of public revenue is at risk per year from the uncontrolled spread of P. ramorum and Phytophthora kernoviae Brasier, Beales \& Kirk (Brasier et al. 2005; Drake and Jones 2017). P. kernoviae is another introduced, invasive species that has been found in the U.K. and New Zealand. The origin of P. ramorum is currently unknown, but one hypothesis is that it came from the Himalayan region of Asia (Hansen 2015).

In Australia, forest dieback caused by the introduced species $P h y$ tophthora cinnamomi Rands (1922) has had negative impacts on fauna habitats (Garkaklis et al. 2004). The origin of P. cinnamomi is also unknown, although speculation centers on Taiwan and the islands of Southeast Asia and the Pacific (Hansen 2015).

In Japan, Phytophthora species are listed as quarantine organisms, with the exception of Phytophthora nicotianae, because it is already a dominant pathogen in Japan, infecting at least 77 plant species in 41 families (Database of Plant Disease in Japan in the Genebank Project, National Agriculture and Food Research Organization). In February 2015, discolored leaves were found on a Rhododendron sp. cultivar Loch Lomond, which was being imported from Scotland to Japan, and the isolate was identified as P. ramorum (Sakoda et al. 2017). This detection at entry suggests that careful import inspections are required, even if a phytosanitary certificate is attached to imported plants (Sakoda et al. 2017).

For the effective quarantine control of plant pathogens, rapid and accurate detection methods are essential. Previously, Phytophthora genus-specific PCR primers have been designed using the following sequences: the ribosomal DNA internal transcribed spacer (rDNA-ITS) region (Scibetta et al. 2012); the Ypt1 gene that encodes the ras-like GTP-binding protein (Schena et al. 2006, 2008); the mitochondrial cytochrome c oxidase subunit 1 and subunit 2 genes (Martin et al. 2004); and two mitochondrial regions, trnM-trnM and atp9-nad9 (Bilodeau et al. 2014). Another detection technique, called recombinase polymerase amplification (RPA), has been established for Phytophthora spp. and provides species-specific assays for $P$. ramorum and $P$. kernoviae (Miles et al. 2015). However, as far as we know these detection methods have been tested only with a limited number of species: at most, 136 of 188 available Phytophthora taxa including subspecies, 
Table 1. Isolates used in this study with their QProbe region allele numbers (see Table 3) and results of assays with the Phytophthora genus-specific LAMP primers with or without the Phytophthora nicotianae-specific QProbe

\begin{tabular}{|c|c|c|c|c|c|c|}
\hline Species & Clade ${ }^{a}$ & Isolate $^{\mathbf{b}}$ & $\begin{array}{l}\text { Allele number of } \\
\text { QProbe region }\end{array}$ & $\begin{array}{l}\text { Detection of genus } \\
\text { by LAMPd }\end{array}$ & $\begin{array}{l}\text { Detection of genus by } \\
\text { LAMP with QProbed }\end{array}$ & $\begin{array}{l}\text { Detection of } P \text {. nicotianae } \\
\text { by LAMP with QProbed }\end{array}$ \\
\hline \multicolumn{7}{|l|}{ Phytophthora } \\
\hline P. nicotianae & 1 & CBS 305.29 & Original & $t^{*}$ & $t^{*}$ & $t^{*}$ \\
\hline P. nicotianae & 1 & CBS 535.92 & Original & $+^{*}$ & + & + \\
\hline P. nicotianae & 1 & MAFF 235436 & Original & + & + & + \\
\hline P. nicotianae & 1 & MAFF 237653 & Original & + & + & + \\
\hline P. nicotianae & 1 & MAFF 238148 & Original & + & + & + \\
\hline P. nicotianae & 1 & MAFF 238150 & Original & + & + & + \\
\hline P. nicotianae & 1 & MAFF 238152 & Original & + & + & + \\
\hline P. nicotianae & 1 & MAFF 238154 & Original & + & + & + \\
\hline P. nicotianae & 1 & MAFF 239554 & Original & + & + & + \\
\hline P. nicotianae & 1 & MAFF 242197 & Original & + & + & + \\
\hline P. nicotianae & 1 & MAFF 305591 & Original & + & + & + \\
\hline P. nicotianae & 1 & MAFF 305795 & Original & + & + & + \\
\hline P. nicotianae & 1 & MAFF 305796 & Original & + & + & + \\
\hline P. nicotianae & 1 & MAFF 305797 & Original & + & + & + \\
\hline P. nicotianae & 1 & MAFF 305799 & Original & + & + & + \\
\hline P. nicotianae & 1 & MAFF 305926 & Original & + & + & + \\
\hline P. nicotianae & 1 & MAFF 305939 & Original & + & + & + \\
\hline P. nicotianae & 1 & MAFF 305940 & Original & + & + & + \\
\hline P. nicotianae & 1 & MAFF 712194 & Original & + & + & + \\
\hline P. nicotianae & 1 & MAFF 712287 & Original & + & + & + \\
\hline P. nicotianae & 1 & MAFF 712342 & Original & + & + & + \\
\hline P. aleatoria & 1 & NZFS 4037 & Allele 1 & NT & NT & NT \\
\hline P. cactorum & $1 \mathrm{a}$ & MAFF 731066 & Allele 1 & $+*$ & $+*$ & $-*$ \\
\hline P. hedraiandra & $1 \mathrm{a}$ & CBS 111725 & Allele 1 & + & $+*$ & _* \\
\hline P. idaei & 1a & WPC P6767 & Allele 1 & + & $+*$ & _* \\
\hline P. pseudotsugae & $1 \mathrm{a}$ & WPC P10339 & Allele 1 & + & $+*$ & -* \\
\hline P. clandestina & $1 \mathrm{~b}$ & WPC P3943 & Allele 12 & + & $+*$ & -* \\
\hline P. iranica & $1 \mathrm{~b}$ & WPC P3882 & Allele 12 & + & $+^{*}$ & -* \\
\hline P. tentaculata & $1 \mathrm{~b}$ & CBS 552.96 & Allele 18 & + & $+*$ & -* \\
\hline$P$. andina & $1 \mathrm{c}$ & CBS 115547 & Allele 5 & + & $+*$ & -* \\
\hline P. infestans & $1 \mathrm{c}$ & MAFF 236324 & Allele 5 & $+^{*}$ & $+^{*}$ & -* \\
\hline P. ipomoeae & $1 \mathrm{c}$ & WPC P10225 & Allele 21 & + & $+*$ & -* \\
\hline P. mirabilis & $1 \mathrm{c}$ & WPC P3005 & Allele 5 & $\begin{array}{l}+ \\
+\end{array}$ & $+*$ & - \\
\hline P. phaseoli & $1 \mathrm{c}$ & WPC P10145 & Allele 5 & + & $+*$ & -* \\
\hline P. urerae & $1 \mathrm{c}$ & PSR27 & Allele 5 & NT & NT & NT \\
\hline P. acaciae & 2 & $\mathrm{ANO2}$ & Allele 10 & NT & NT & NT \\
\hline P. mengei & 2 & ATCC MYA-4554 & Allele 1 & + & NT & NT \\
\hline P. multivesiculata & 2 & CBS 545.96 & Allele 1 & + & NT & NT \\
\hline P. siskiyouensis & 2 & ATCC MYA-4187 & Allele 1 & + & NT & NT \\
\hline P. tropicalis & 2 & CBS 434.91 & Allele 1 & + & NT & NT \\
\hline P. oleae & 2 & Pola & Allele 1 & NT & NT & NT \\
\hline P. botryosa & $2 \mathrm{a}$ & CBS 581.69 & Allele 1 & + & NT & NT \\
\hline P. citrophthora & $2 \mathrm{a}$ & WPC P0479 & Allele 1 & $+^{*}$ & + & - \\
\hline P. colocasiae & $2 \mathrm{a}$ & WPC P6317 & Allele 1 & + & NT & NT \\
\hline P. himalsilva & $2 \mathrm{a}$ & CBS 128767 & Allele 1 & + & NT & NT \\
\hline P. meadii & $2 \mathrm{a}$ & CBS 219.88 & Allele 1 & + & NT & NT \\
\hline P. mekongensis & $2 \mathrm{a}$ & CBS 135136 & Allele 1 & + & NT & NT \\
\hline P. occultans & $2 \mathrm{a}$ & CBS 101557 & Allele 1 & + & NT & NT \\
\hline P. terminalis & $2 \mathrm{a}$ & WPC P19956 & Allele 1 & + & NT & NT \\
\hline P. amaranthi & $2 \mathrm{~b}$ & WPC P20892 & Allele 1 & + & NT & NT \\
\hline P. capsici & $2 b$ & MAFF 305920 & Allele 1 & $+^{*}$ & + & - \\
\hline P. glovera & $2 b$ & CBS 121969 & Allele 1 & + & NT & NT \\
\hline P. acerina & $2 \mathrm{c}$ & CBS 133931 & Allele 1 & + & NT & NT \\
\hline P. capensis & $2 \mathrm{c}$ & WPC P1819 & Allele 1 & + & NT & NT \\
\hline P. caryae & $2 \mathrm{c}$ & ATCC TSD-54 & Allele 1 & + & NT & NT \\
\hline P. citricola & $2 \mathrm{c}$ & CH95PHE28 & Allele 1 & $+*$ & + & - \\
\hline & & & & & & (Continued on next page) \\
\hline
\end{tabular}

a Clade designations are from Abad et al. (2019).

b ATCC, American Type Culture Collection; CBS, Westerdijk Fungal Biodiversity Institute; CCIBt, Institute of Botany Culture Collection; ICMP, International Collection of Microorganisms from Plants; IMI, International Mycological Institute Herbarium; MAFF, Japanese Ministry of Agriculture Forestry and Fisheries; NBRC, National Institute of Technology and Evaluation Biological Resource Center; NZFS, New Zealand Forest Service; WPC, World Phytophthora Genetic Resource Collection.

${ }^{\mathrm{c}}$ The sequences of the QProbe regions are classified into alleles (original plus numbers 1 to 26; see Table 3) based on the rDNA-ITS sequences with NCBI accession numbers listed in Supplementary Table S1.

d At least two repeats were performed. +, detected within $60 \mathrm{~min}$;-, not detected within $60 \mathrm{~min}$; NT, not tested. Asterisks indicate samples that were tested and confirmed using the ABI StepOnePlus Real-Time PCR System. 
Table 1. (Continued from previous page)

\begin{tabular}{|c|c|c|c|c|c|c|}
\hline Species & Clade & Isolate $^{\mathbf{b}}$ & $\begin{array}{l}\text { Allele number of } \\
\text { QProbe region }\end{array}$ & $\begin{array}{l}\text { Detection of genus } \\
\text { by LAMPd }\end{array}$ & $\begin{array}{l}\text { Detection of genus by } \\
\text { LAMP with QProbed }^{d}\end{array}$ & $\begin{array}{l}\text { Detection of } P \text {. nicotianae } \\
\text { by LAMP with QProbed }\end{array}$ \\
\hline P. multivora & $2 \mathrm{c}$ & NBRC 31016 & Allele 1 & + & NT & NT \\
\hline P. pachypleura & $2 \mathrm{c}$ & IMI 502404 & Allele 1 & + & NT & NT \\
\hline P. pini & $2 \mathrm{c}$ & CBS 181.25 & Allele 1 & + & NT & NT \\
\hline P. plurivora & $2 \mathrm{c}$ & CBS 124093 & Allele 1 & + & NT & NT \\
\hline P. bishii & $2 \mathrm{~d}$ & CBS 122081 & Allele 10 & + & NT & NT \\
\hline P. elongata & $2 \mathrm{~d}$ & CBS 125799 & Allele 1 & + & NT & NT \\
\hline P. frigida & $2 \mathrm{~d}$ & CBS 121941 & Allele 20 & + & + & - \\
\hline P. ilicis & $3 a$ & WPC P3939 & Allele 1 & + & NT & NT \\
\hline P. nemorosa & $3 a$ & $\mathrm{C} 71$ & Allele 1 & $t^{*}$ & + & - \\
\hline P. pluvialis & $3 a$ & ATCC MYA-4930 & Allele 1 & + & NT & NT \\
\hline P. pseudosyringae & $3 a$ & CBS 111772 & Allele 1 & + & NT & NT \\
\hline P. psychrophila & $3 \mathrm{a}$ & CBS 803.95 & Allele 1 & + & NT & NT \\
\hline P. castanetorum & $3 b$ & CBS 142299 & Allele 1 & + & NT & NT \\
\hline P. quercina & $3 b$ & WPC P10439 & Allele 1 & + & NT & NT \\
\hline P. tubulina & $3 b$ & CBS 141212 & Allele 23 & + & + & - \\
\hline P. alticola & 4 & CBS 121939 & Allele 1 & + & NT & NT \\
\hline P. arenaria & 4 & CBS 127950 & Allele 1 & + & NT & NT \\
\hline P. boodjera & 4 & CBS 138637 & Allele 1 & + & NT & NT \\
\hline P. megakarya & 4 & WPC P1672 & Allele 10 & + & NT & NT \\
\hline P. palmivora & 4 & CH88-1 & Allele 10 & $t^{*}$ & + & - \\
\hline P. quercetorum & 4 & WPC P15555 & Allele 1 & + & NT & NT \\
\hline P. agathidicida & 5 & ICMP 17027 & Allele 5 & + & NT & NT \\
\hline P. castaneae & 5 & ICMP 19434 & Allele 5 & + & NT & NT \\
\hline P. cocois & 5 & ICMP 16948 & Allele 5 & + & NT & NT \\
\hline P. heveae & 5 & WPC P1102 & Allele 5 & $t^{*}$ & + & - \\
\hline P. sp. novaeguineae & 5 & ICMP 19637 & Allele 5 & + & NT & NT \\
\hline P. asparagi & 6 & CBS 132095 & Allele 19 & $t^{*}$ & + & - \\
\hline P. lacustris & 6 & WPC P10337 & Allele 2 & + & NT & NT \\
\hline P. balyanboodja & $6 a$ & CBS 143058 & Allele 2 & NT & NT & NT \\
\hline P. chesapeakensis & $6 a$ & CBS 140655 & Allele 2 & NT & NT & NT \\
\hline P. condilina & $6 a$ & CBS 143059 & Allele 2 & NT & NT & NT \\
\hline P. cooljarloo & $6 a$ & CBS 143062 & Allele 2 & NT & NT & NT \\
\hline P. gemini & $6 a$ & CBS 123381 & Allele 2 & + & NT & NT \\
\hline P. humicola & $6 a$ & CBS 200.81 & Allele 2 & $t^{*}$ & + & - \\
\hline P. inundata & $6 \mathrm{a}$ & WPC P8478 & Allele 2 & + & NT & NT \\
\hline P. kwongonina & $6 a$ & CBS 143060 & Allele 2 & NT & NT & NT \\
\hline P. oreophila & $6 a$ & U11 & Allele 2 & NT & NT & NT \\
\hline P. pseudorosacearum & $6 a$ & CBS 143061 & Allele 2 & NT & NT & NT \\
\hline P. rosacearum & $6 a$ & ATCC MYA-4456 & Allele 2 & + & NT & NT \\
\hline P. ×stagnum & $6 b$ & ATCC MYA-4926 & Allele 2 & + & NT & NT \\
\hline P. amnicola & $6 b$ & CBS 131652 & Allele 2 & + & NT & NT \\
\hline P. bilorbang & $6 \mathrm{~b}$ & CBS 131653 & Allele 2 & + & NT & NT \\
\hline P. borealis & $6 b$ & ATCC MYA-4881 & Allele 2 & + & NT & NT \\
\hline P. chlamydospora & $6 \mathrm{~b}$ & WPC P6133 & Allele 2 & + & NT & NT \\
\hline P. crassamura & $6 b$ & CBS 140357 & Allele 2 & + & NT & NT \\
\hline P. fluvialis & $6 \mathrm{~b}$ & CBS 129424 & Allele 2 & + & NT & NT \\
\hline P. gibbosa & $6 b$ & CBS 127951 & Allele 2 & + & NT & NT \\
\hline P. gonapodyides & $6 b$ & WPC P7050 & Allele 2 & + & NT & NT \\
\hline P. gregata & $6 \mathrm{~b}$ & CH97TUL2 & Allele 2 & + & NT & NT \\
\hline P. litoralis & $6 b$ & CBS 127953 & Allele 2 & + & NT & NT \\
\hline P. megasperma & $6 b$ & CBS 402.72 & Allele 2 & + & NT & NT \\
\hline P. mississippiae & $6 \mathrm{~b}$ & ATCC MYA-4946 & Allele 2 & + & NT & NT \\
\hline P. moyootj & $6 b$ & CBS 138759 & Allele 2 & + & NT & NT \\
\hline P. ornamentata & $6 \mathrm{~b}$ & CBS 140647 & Allele 2 & + & NT & NT \\
\hline P. pinifolia & $6 b$ & CBS 122924 & Allele 2 & + & NT & NT \\
\hline$P$. riparia & $6 b$ & ATCC MYA-4882 & Allele 2 & + & NT & NT \\
\hline P. thermophila & $6 b$ & CBS 127954 & Allele 2 & + & NT & NT \\
\hline P. $\times$ cambivora & $7 \mathrm{a}$ & CBS 141218 & Allele 3 & + & NT & NT \\
\hline P. ×heterohybrida & $7 \mathrm{a}$ & CBS 141207 & Allele 3 & + & NT & NT \\
\hline P. xincrassata & $7 \mathrm{a}$ & CBS 141209 & Allele 3 & + & NT & NT \\
\hline P. attenuata & $7 \mathrm{a}$ & CBS 141199 & Allele 3 & + & NT & NT \\
\hline P. cinnamomi & $7 \mathrm{a}$ & NBRC 33180 & Allele 3 & + & NT & NT \\
\hline P. europaea & $7 \mathrm{a}$ & CBS 109049 & Allele 3 & + & NT & NT \\
\hline P. flexuosa & $7 \mathrm{a}$ & CBS 141201 & Allele 3 & + & NT & NT \\
\hline P. formosa & $7 \mathrm{a}$ & CBS 141203 & Allele 3 & + & NT & NT \\
\hline \multirow[t]{2}{*}{ P. fragariae } & $7 \mathrm{a}$ & CBS 209.46 & Allele 3 & + & NT & NT \\
\hline & & & & & & (Continued on next page) \\
\hline
\end{tabular}


Table 1. (Continued from previous page)

\begin{tabular}{|c|c|c|c|c|c|c|}
\hline Species & Clade $^{\mathbf{a}}$ & Isolate $^{\mathbf{b}}$ & $\begin{array}{l}\text { Allele number of } \\
\text { QProbe region }\end{array}$ & $\begin{array}{l}\text { Detection of genus } \\
\text { by LAMPd }\end{array}$ & $\begin{array}{l}\text { Detection of genus by } \\
\text { LAMP with QProbed }\end{array}$ & $\begin{array}{l}\text { Detection of } P \text {. nicotianae } \\
\text { by LAMP with QProbe }^{\text {d }}\end{array}$ \\
\hline P. intricata & $7 \mathrm{a}$ & CBS 141211 & Allele 3 & + & NT & NT \\
\hline P. parvispora & $7 \mathrm{a}$ & CBS 411.96 & Allele 3 & + & NT & NT \\
\hline P. rubi & $7 \mathrm{a}$ & CBS 967.95 & Allele 3 & + & NT & NT \\
\hline P. tyrrhenica & $7 \mathrm{a}$ & CBS 142301 & Allele 3 & + & NT & NT \\
\hline P. uliginosa & $7 \mathrm{a}$ & CBS 109054 & Allele 3 & + & NT & NT \\
\hline P. vulcanica & $7 \mathrm{a}$ & CBS 141216 & Allele 3 & + & NT & NT \\
\hline P. asiatica & $7 b$ & CBS 133347 & Allele 3 & + & NT & NT \\
\hline P. cajani & $7 b$ & WPC P3105 & Allele 3 & $t^{*}$ & + & - \\
\hline P. melonis & $7 b$ & CBS 582.69 & Allele 3 & + & NT & NT \\
\hline P. niederhauserii & $7 b$ & CH96HE1 & Allele 3 & + & NT & NT \\
\hline P. pisi & $7 b$ & CBS 130350 & Allele 3 & + & NT & NT \\
\hline P. pistaciae & $7 b$ & CBS 137185 & Allele 3 & + & NT & NT \\
\hline P. sojae & $7 b$ & $\mathrm{Pm}-1$ & Allele 3 & + & NT & NT \\
\hline P. vignae & $7 b$ & NBRC 30613 & Allele 3 & + & NT & NT \\
\hline $\begin{array}{l}\text { P. cinnamomi var. } \\
\text { robiniae }\end{array}$ & $7 \mathrm{c}$ & ATCC 90456 & Allele 3 & + & NT & NT \\
\hline P. fragariaefolia & $7 \mathrm{c}$ & CBS 135747 & Allele 3 & + & NT & NT \\
\hline P. nagaii & $7 \mathrm{c}$ & CBS 133248 & Allele 3 & + & NT & NT \\
\hline P. himalayensis & 8 & CBS 357.59 & Allele 7 & NT & NT & NT \\
\hline P. cryptogea & $8 \mathrm{a}$ & CBS 113.19 & Allele 7 & $+*$ & + & - \\
\hline P. drechsleri & $8 \mathrm{a}$ & CBS 292.35 & Allele 25 & + & + & - \\
\hline P. erythroseptica & $8 \mathrm{a}$ & WPC P0340 & Allele 7 & + & + & - \\
\hline P. medicaginis & $8 \mathrm{a}$ & WPC P7029 & Allele 6 & + & NT & NT \\
\hline P. pseudocryptogea & $8 \mathrm{a}$ & CBS 139749 & Allele 7 & + & NT & NT \\
\hline P. richardiae & $8 \mathrm{a}$ & CBS 240.30 & Allele 14 & + & + & - \\
\hline P. sansomeana & $8 \mathrm{a}$ & WPC P3163 & Allele 7 & + & + & - \\
\hline P. sp. kelmania & $8 \mathrm{a}$ & GF649 & Allele 7 & + & NT & NT \\
\hline P. trifolii & $8 \mathrm{a}$ & WPC P6980 & Allele 6 & + & NT & NT \\
\hline P. brassicae & $8 b$ & CBS 179.87 & Allele 6 & $t^{*}$ & + & - \\
\hline P. cichorii & $8 \mathrm{~b}$ & CBS 115029 & Allele 22 & + & + & - \\
\hline P. dauci & $8 b$ & CBS 127102 & Allele 6 & $t^{*}$ & + & - \\
\hline P. lactucae & $8 b$ & BPIC 1985 & Allele 6 & + & NT & NT \\
\hline P. porri & $8 b$ & CBS 140.87 & Allele 6 & + & NT & NT \\
\hline P. primulae & $8 b$ & WPC P10333 & Allele 6 & + & NT & NT \\
\hline P. pseudolactucae & $8 b$ & CBS 137103 & Allele 6 & + & NT & NT \\
\hline P. foliorum & $8 \mathrm{c}$ & WPC P10974 & Allele 8 & $t^{*}$ & + & - \\
\hline P. hibernalis & $8 \mathrm{c}$ & WPC P3822 & Allele 9 & + & + & - \\
\hline P. lateralis & $8 \mathrm{c}$ & CBS 168.42 & Allele 9 & $+^{*}$ & + & - \\
\hline P. ramorum & $8 \mathrm{c}$ & CBS 101553 & Allele 9 & $t^{*}$ & + & - \\
\hline P. ramorum & $8 \mathrm{c}$ & Pr-1 & Allele 9 & $t^{*}$ & NT & NT \\
\hline P. austrocedri & $8 \mathrm{~d}$ & ATCC MYA-4074 & Allele 8 & + & NT & NT \\
\hline P. obscura & $8 \mathrm{~d}$ & CBS 129273 & Allele 8 & + & NT & NT \\
\hline P. syringae & $8 \mathrm{~d}$ & FIUm1 & Allele 8 & $+*$ & + & - \\
\hline P. cacuminis & 9 & $\mathrm{U} 40$ & Allele 11 & NT & NT & NT \\
\hline P. estuarina & 9 & CCIBt 4157 & Allele 16 & NT & NT & NT \\
\hline P. pseudopolonica & 9 & CBS 142610 & Allele 17 & NT & NT & NT \\
\hline P. rhizophorae & 9 & CCIBt 4152 & Allele 4 & NT & NT & NT \\
\hline P. aquimorbida & $9 \mathrm{a}$ & ATCC MYA-4578 & Allele 16 & + & + & - \\
\hline P. chrysanthemi & $9 \mathrm{a}$ & CBS 123163 & Allele 4 & + & NT & NT \\
\hline P. hydrogena & $9 \mathrm{a}$ & ATCC MYA-4919 & Allele 4 & + & NT & NT \\
\hline P. hydropathica & $9 a$ & ATCC MYA-4460 & Allele 15 & + & NT & NT \\
\hline P. irrigata & $9 \mathrm{a}$ & ATCC MYA-4457 & Allele 26 & + & + & - \\
\hline P. macilentosa & $9 a$ & ATCC MYA-4945 & Allele 24 & + & NT & NT \\
\hline P. parsiana & $9 \mathrm{a}$ & $\mathrm{C} 25$ & Allele 15 & + & + & - \\
\hline P. sp. cuyabensis & $9 \mathrm{a}$ & WPC P8213 & Allele 4 & + & NT & NT \\
\hline P. sp. lagoariana & $9 \mathrm{a}$ & WPC P8217 & Allele 4 & + & NT & NT \\
\hline P. virginiana & $9 \mathrm{a}$ & ATCC MYA-4927 & Allele 4 & + & NT & NT \\
\hline P. insolita & $9 b$ & WPC P6195 & Allele 13 & $t^{*}$ & + & - \\
\hline P. polonica & $9 b$ & CBS 119650 & Allele 17 & + & + & - \\
\hline P. prodigiosa & $9 b$ & CBS 135138 & Allele 13 & + & + & - \\
\hline P. captiosa & $10 \mathrm{a}$ & NZFS 310C & Allele 11 & NT & NT & NT \\
\hline P. constricta & $10 \mathrm{a}$ & CBS 125801 & Allele 11 & + & NT & NT \\
\hline P. fallax & $10 \mathrm{a}$ & NZFS310L & Allele 11 & + & NT & NT \\
\hline P. macrochlamydospora & $10 \mathrm{a}$ & WPC P10263 & Allele 14 & + & NT & NT \\
\hline P. quininea & $10 \mathrm{a}$ & CBS 407.48 & Allele 8 & + & NT & NT \\
\hline P. richardiae & $10 \mathrm{a}$ & WPC P7789 & Allele 14 & + & + & $\begin{array}{c}- \\
\text { (Continued on next page) }\end{array}$ \\
\hline
\end{tabular}


Table 1. (Continued from previous page)

\begin{tabular}{|c|c|c|c|c|c|c|}
\hline Species & Clade $^{\mathbf{a}}$ & Isolate $^{\mathbf{b}}$ & $\begin{array}{l}\text { Allele number of } \\
\text { QProbe region }\end{array}$ & $\begin{array}{l}\text { Detection of genus } \\
\text { by LAMPd }\end{array}$ & $\begin{array}{l}\text { Detection of genus by } \\
\text { LAMP with QProbed }\end{array}$ & $\begin{array}{l}\text { Detection of } P \text {. nicotianae } \\
\text { by LAMP with QProbe }\end{array}$ \\
\hline P. boehmeriae & $10 \mathrm{~b}$ & WPC P6950 & Allele 4 & + & NT & NT \\
\hline$P$. gallica & $10 \mathrm{~b}$ & WPC P16826 & Allele 4 & + & NT & NT \\
\hline P. gondwanensis & $10 \mathrm{~b}$ & CBS 139336 & Allele 4 & NT & NT & NT \\
\hline P. intercalaris & $10 \mathrm{~b}$ & CBS 140632 & Allele 4 & + & NT & NT \\
\hline P. kernoviae & $10 \mathrm{~b}$ & $\mathrm{P} 1571$ & Allele 4 & $+^{*}$ & + & - \\
\hline P. morindae & $10 \mathrm{~b}$ & CBS 121982 & Allele 4 & + & NT & NT \\
\hline P. lilii & New clade & CBS 135746 & Allele 1 & + & + & - \\
\hline P. stricta & New clade & ATCC MYA-4944 & Allele 1 & + & NT & NT \\
\hline \multicolumn{7}{|l|}{ Pythium } \\
\hline Py. adhaerens & A & CBS 520.74 & & $-*$ & - & - \\
\hline Py. myriotylum & B1 & NBRC 100113 & & $-*$ & - & - \\
\hline Py. pyrilobum & $\mathrm{B} 1 / \mathrm{B} 2$ & NBRC 107365 & & $-*$ & - & - \\
\hline Py. dissotocum & $\mathrm{B} 2$ & MAFF 305576 & & $-^{*}$ & - & - \\
\hline Py. acanthicum & $\mathrm{D}$ & MAFF 241099 & & $-*$ & - & - \\
\hline Py. hypogynum & E1 & CBS 234.94 & & $-*$ & - & - \\
\hline Py. middletonii & E2 & CBS 528.74 & & $-*$ & - & - \\
\hline Py. irregulare & $\mathrm{F}$ & CBS 263.30 & & $-*$ & - & - \\
\hline Py. paddicum & $\mathrm{G}$ & MAFF 241108 & & $-*$ & - & - \\
\hline Py. anandrum & $\mathrm{H}$ & CBS 285.31 & & $-*$ & - & - \\
\hline $\begin{array}{l}\text { Py. ultimum var. } \\
\text { ultimum }\end{array}$ & I & NBRC 100122 & & $-*$ & - & - \\
\hline Py. nunn & $\mathrm{J}$ & CBS 808.96 & & $-*$ & - & - \\
\hline \multicolumn{7}{|l|}{ Phytopythium } \\
\hline Pp. aichiense & - & CBS 137195 & & - & NT & NT \\
\hline Pp. boreale & - & CBS 551.88 & & - & NT & NT \\
\hline Pp. carbonicum & - & CBS 112544 & & - & NT & NT \\
\hline Pp. chamaehyphon & - & CBS 259.30 & & - & NT & NT \\
\hline Pp. citrinum & - & CBS 119171 & & - & NT & NT \\
\hline Pp. cucurbitacearum & - & CBS 748.96 & & - & NT & NT \\
\hline Pp. delawarense & - & $382 B$ & & + & - & - \\
\hline Pp. fagopyri & - & CBS 137105 & & + & + & - \\
\hline Pp. helicoides & - & NBRC 100107 & & $-*$ & - & - \\
\hline Pp. iriomotense & - & CBS 137104 & & - & NT & NT \\
\hline Pp. litorale & - & T1a2-17 & & - & NT & NT \\
\hline Pp. megacrpum & - & CBS 112351 & & - & NT & NT \\
\hline Pp. mercuriale & - & CBS 122443 & & - & NT & NT \\
\hline Pp. montanum & - & CBS 111349 & & - & NT & NT \\
\hline Pp. oedochilum & - & CBS 292.37 & & - & NT & NT \\
\hline Pp. ostracodes & - & CBS 768.73 & & - & NT & NT \\
\hline Pp. vexans & - & 2D111 & & - & - & - \\
\hline \multicolumn{7}{|l|}{$\begin{array}{l}\text { Other soil-borne } \\
\text { pathogens }\end{array}$} \\
\hline $\begin{array}{l}\text { Aphanomyces } \\
\text { cochlioides }\end{array}$ & - & GFHT6 & & - & - & - \\
\hline $\begin{array}{l}\text { Fusarium oxysporum } \\
\text { f. sp. fragariae }\end{array}$ & - & MAFF 727510 & & - & - & - \\
\hline $\begin{array}{l}\text { Plasmodiophora } \\
\text { brassicae }\end{array}$ & - & HY & & - & - & - \\
\hline Rhizoctonia solani & - & S02 & & - & - & - \\
\hline $\begin{array}{l}\text { Saprolegnia } \\
\text { parasitica }\end{array}$ & - & NBRC 32708 & & - & - & - \\
\hline $\begin{array}{l}\text { Sclerotinia } \\
\text { sclerotiorum }\end{array}$ & - & AiTog & & - & - & - \\
\hline $\begin{array}{l}\text { Verticillium albo- } \\
\text { atrum }\end{array}$ & - & Vaal 130308 & & - & - & - \\
\hline
\end{tabular}

varieties, and hybrids. The potential number of Phytophthora species is estimated to be between 200 and 600 (Brasier 2009). Accordingly, we have updated the genus-specific detection method and confirmed its specificity using a wide range of taxa including some newly discovered Phytophthora species.

The advantages of loop-mediated isothermal amplification (LAMP)-based detection methods include rapidity (detection in about $30 \mathrm{~min}$ ), high tolerance to inhibitors from biological sources (Kaneko et al. 2007), and broader applicability from the laboratory to the field, as demonstrated by numerous studies (Mori and Notomi 2009; Mori et al. 2001; Nagamine et al. 2002; Notomi et al. 2000). The use of a quenching probe (QProbe)
(Kurata et al. 2001) allows for the simultaneous, quantitative detection of a specific mutation among sequences amplified in the LAMP assay. A QProbe is a single-stranded oligonucleotide that has a cytosine labeled with a fluorophore. When the QProbe hybridizes with its target sequence, the fluorescence is quenched by electron transfer between the fluorophore and a guanine residue in the target. Even a single nucleotide mutation in the target sequence of a LAMP product can be detected using a QProbe (Ayukawa et al. 2017).

In this study, we developed a LAMP-based simultaneous detection method for the genus Phytophthora and the species P. nicotianae, by using a genus-specific LAMP primer and a species-specific QProbe. 


\section{Materials and Methods}

Isolates and mycelial DNA extraction. The isolates used in this study are listed in Table 1. They were grown on V8 agar plates at $25^{\circ} \mathrm{C}$. Mycelial samples were collected by scraping with an inoculating needle, and the DNA was extracted in the PrepMan Ultra Sample Preparation Reagent (Thermo Fisher Scientific, Waltham, MA) using the manufacturer's protocol. Total DNA concentration was measured using the QuantiFluor dsDNA System (Promega, Tokyo, Japan) with a Qubit2.0 Fluorometer (Invitrogen, Tokyo, Japan). The concentration was adjusted to $100 \mathrm{pg} / \mu \mathrm{l}$ with TE buffer (10 mM Tris- $\mathrm{HCl}, 1 \mathrm{mM}$ EDTA, $\mathrm{pH} \mathrm{8.0),} \mathrm{and} \mathrm{the} \mathrm{samples} \mathrm{were}$ stored at $4{ }^{\circ} \mathrm{C}$ until used.

LAMP primer and QProbe design. The conserved regions within the rDNA-ITS regions of Phytophthora species were identified using a multiple alignment analysis (Supplementary Figure S1), and LAMP primers were designed using Primer Explorer V5 software (https://primerexplorer.jp). The LAMP primer set included the F3, B3, FIP (F1c to F2), and BIP (B1c to B2) primers without Fand B-loop primers. For simultaneous detection, a $P$. nicotianaespecific QProbe was designed using a QProbe design tool in Microsoft Excel (provided by Nippon Steel Eco-Tech Corp., Tsukuba, Japan). The sequences of the LAMP primers and QProbe are based on the rDNA-
ITS sequence (NCBI: HQ643363; https://www.ncbi.nlm.nih.gov/ nucleotide/) of $P$. nicotianae isolate CBS 305.29 (from the CBSKNAW collection, Westerdijk Fungal Biodiversity Institute). The NCBI accession numbers of other rDNA-ITS sequences used in the multiple alignments are shown in Supplementary Table S1.

DNA sample preparation from inoculated and naturally infected plants. To inoculate plants, $P$. nicotianae and $P$. capsic $i$ isolates were grown on V8 agar for 4 days, and $7 \mathrm{~mm}$ diameter mycelial disks were taken from actively growing colonies. Tomato and eggplant fruits were placed on wet paper towels in plastic trays and inoculated with the mycelial disks. The trays were covered with polyethylene bags to maintain high humidity and incubated in a growth chamber (12-h light/dark cycle) at $25^{\circ} \mathrm{C}$ for 3 days. After incubation, 5-mm squares of infected tissue were cut into small pieces with razor blades and collected in 1.5-ml Eppendorf tubes, then subjected to DNA extraction. Lesions of naturally infected periwinkle and tobacco stems were shaved off the stems with a knife, and two samples ( $5 \mathrm{~mm}$ lengths) from each plant were cut into small pieces and collected in 1.5-ml Eppendorf tubes, then subjected to DNA extraction.

DNA extraction was performed using the Kaneka Easy DNA Extraction Kit version 2, following the manufacture's protocol. All

Table 2. Sequences of the Phytophthora genus-specific LAMP primer set and the Phytophthora nicotianae-specific QProbe

\begin{tabular}{|c|c|c|c|c|}
\hline & & Jame & Sequence $\left(5^{\prime}-3^{\prime}\right)$ & Length (bp) \\
\hline \multirow{4}{*}{$\begin{array}{l}\text { Phytophthora genus-specific LAMP } \\
\text { primer set }\end{array}$} & Physp & $\mathrm{F} 3$ & TCTGCTTTTAACTAGATAGC & 20 \\
\hline & & B3 & CACCACTTTTCGAGCAAAGA & 20 \\
\hline & & FIP & GCATACTTCCAGGACTAACCGTAATGCGAATTGCAGGA & 38 \\
\hline & & BIP & CCTGTATCAGTGTCCGTACATCTCCTCCACCGACTACACG & 40 \\
\hline P. nicotianae-specific QProbe & PnicQP & QProbe-3G & CCGTACATTAAACTTGACTTTCTTCC & 26 \\
\hline
\end{tabular}

Table 3. Allele numbers of the QProbe regions with their sequences and experimentally identified negative peak temperatures

\begin{tabular}{|c|c|c|c|c|c|c|}
\hline $\begin{array}{l}\text { Allele } \\
\text { number }\end{array}$ & $\begin{array}{c}\text { Number of } \\
\text { species (Total: } \\
\text { 175) }\end{array}$ & Sequence of QProbe region ${ }^{b}$ & Representative species & Isolate $^{c}$ & $\begin{array}{c}\text { Negative peak } \\
\text { temperature }\left({ }^{\circ} \mathrm{C}\right) \\
\left(\begin{array}{c}\text { Average } \pm \mathrm{SE}, \\
\mathbf{n}=3)\end{array}\right.\end{array}$ & $\begin{array}{c}\text { Delta } \\
\text { temperature }\left({ }^{\circ} \mathrm{C}\right) \\
\text { (Allele-Original) }\end{array}$ \\
\hline Original & 1 & CCGTACATTAAАCTTGACTTTCTTCC & Phytophthora nicotianae & CBS 305.29 & $53.06 \pm 0.03$ & - \\
\hline Allele 1 & 43 & CCGTACAT $\underline{C A A A C T T G g C T T T C T T C C ~}$ & P. cactorum & MAFF 731066 & $42.07 \pm 0.03$ & -11.00 \\
\hline Allele 2 & 30 & 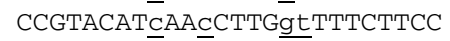 & P. humicola & CBS 200.81 & $<40$ & $<-13$ \\
\hline Allele 3 & 27 & 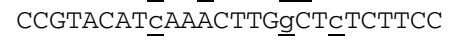 & P. cajani & WPC P3105 & $<40$ & $<-13$ \\
\hline Allele 4 & 12 & 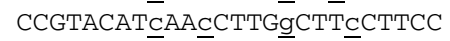 & P. kernoviae & $\mathrm{P} 1571$ & $<40$ & $<-13$ \\
\hline Allele 5 & 10 & 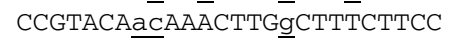 & P. infestans & MAFF 236324 & $42.03 \pm 0.02$ & -11.03 \\
\hline Allele 6 & 8 & CCGTACAaTAAACTTGg्ăCTCCTTCC & P. brassicae & CBS 179.87 & $<40$ & $<-13$ \\
\hline Allele 7 & 6 & 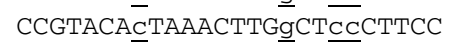 & P. cryptogea & CBS 113.19 & $<40$ & $<-13$ \\
\hline Allele 8 & 5 & CCGTACAT $\overline{\mathrm{CAAACTTG}} \overline{\mathrm{g}} \mathrm{CT} \overline{\mathrm{CC}} \mathrm{CTTCC}$ & P. syringae & FIUm1 & $<40$ & $<-13$ \\
\hline Allele 9 & 4 & 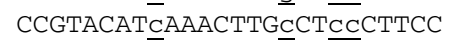 & P. ramorum & CBS 101553 & $<40$ & $<-13$ \\
\hline Allele 10 & 4 & CCGTACAT $\overline{\mathrm{C} A A A C T T G \bar{g} t T T T C T T C C}$ & P. palmivora & CH88-1 & $<40$ & $<-13$ \\
\hline Allele 11 & 4 & CCGTAtAT $\underline{\bar{c} A A A C T T G \underline{C} \mathrm{CTT}} \underline{\mathrm{C}} \mathrm{CTTCC}$ & P. fallax & NZFS310L & $<40$ & $<-13$ \\
\hline Allele 12 & 2 & CCGTACATC्AAACTTGACTTTCTTCC & P. clandestina & WPC P3943 & $48.84 \pm 0.18$ & -4.22 \\
\hline Allele 13 & 2 & 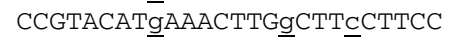 & P. prodigiosa & CBS 135138 & $<40$ & $<-13$ \\
\hline Allele 14 & 2 & 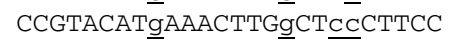 & P. richardiae & WPC P7789 & $<40$ & $<-13$ \\
\hline Allele 15 & 2 & 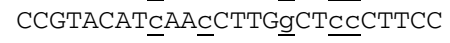 & P. parsiana & $\mathrm{C} 25$ & $<40$ & $<-13$ \\
\hline Allele 16 & 2 & 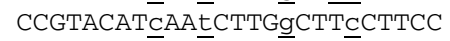 & P. aquimorbida & ATCC MYA-4578 & $<40$ & $<-13$ \\
\hline Allele 17 & 2 & 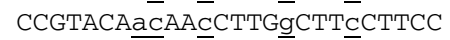 & P. polonica & CBS 119650 & $<40$ & $<-13$ \\
\hline Allele 18 & 1 & CCGTACAT $\underline{\mathrm{C}} \mathrm{AA} \overline{\mathrm{A}} \mathrm{CTTGA} \mathrm{CTTTCTT} \underline{\mathrm{t}}$ & P. tentaculata & CBS 552.96 & $40.94 \pm 0.0003$ & -12.13 \\
\hline Allele 19 & 1 & CCGTACAT $\underline{\mathrm{C} A A} \underline{\mathrm{C}} \mathrm{CTTGg} \underline{\mathrm{g}} \mathrm{CTTCTTC}$ & P. asparagi & CBS 132095 & $<40$ & $<-13$ \\
\hline Allele 20 & 1 & СCGTACAT $\overline{\mathrm{C} A A \bar{A}} \overline{\mathrm{a}} \mathrm{TTG} \overline{\mathrm{g}} \mathrm{CTTTCTTCC}$ & $P$. frigida & CBS 121941 & $<40$ & $<-13$ \\
\hline Allele 21 & 1 & 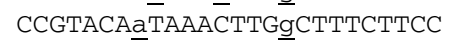 & P. ipomoeae & WPC P10225 & $42.15 \pm 0.08$ & -10.91 \\
\hline Allele 22 & 1 & CCGTACĀ̄TAAACTTGС̆CTCCCTTCC & P. cichorii & CBS 115029 & $<40$ & $<-13$ \\
\hline Allele 23 & 1 & 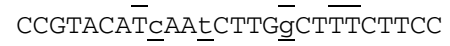 & P. tubulina & CBS 141212 & $<40$ & $<-13$ \\
\hline Allele 24 & 1 & 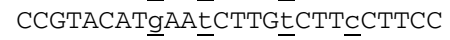 & P. macilentosa & ATCC MYA-4945 & $<40$ & $<-13$ \\
\hline Allele 25 & 1 & 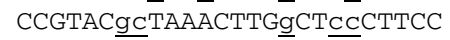 & P. drechsleri & CBS 292.35 & $<40$ & $<-13$ \\
\hline Allele 26 & 1 & 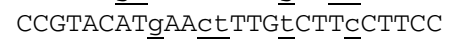 & P. irrigata & ATCC MYA-4457 & $<40$ & $<-13$ \\
\hline
\end{tabular}

a The sequences of the QProbe regions are classified into alleles (original plus numbers 1 to 26 ) based on the rDNA-ITS sequences with NCBI accession numbers listed in Supplementary Table S1.

${ }^{\mathrm{b}}$ Small characters and underlines indicate mismatches with the QProbe sequence.

c ATCC, American Type Culture Collection; CBS, Westerdijk Fungal Biodiversity Institute; MAFF, Japanese Ministry of Agriculture Forestry and Fisheries; NZFS, New Zealand Forest Service; WPC, World Phytophthora Genetic Resource Collection. 
extracts were diluted 20 times with TE buffer, then stored at $4^{\circ} \mathrm{C}$ until used as templates.

LAMP assay using the GenieII system, with or without the QProbe. The LAMP reaction was conducted in a total volume of $25 \mu$ l containing $1 \times$ Isothermal Master Mix (fluorescent dye, Optigene, Horsham, U.K.), $1.6 \mu \mathrm{M}$ each of FIP and BIP primer, $0.2 \mu \mathrm{M}$ each of F3 and B3 primer, and $1 \mu$ l of DNA template. In all assays except the assay used to determine sensitivity and the assays of plant extracts, the mycelial DNA concentration was adjusted to $100 \mathrm{pg} / \mu \mathrm{l}$. A reaction mix containing $1 \mu \mathrm{l}$ sterile distilled water instead of DNA was used as a negative control. The LAMP assay was performed using the portable real-time fluorometer GenieII (Optigene) with the following conditions: preheat $5 \mathrm{~min}$ at $68^{\circ} \mathrm{C}$; amplification $60 \mathrm{~min}$ at $68^{\circ} \mathrm{C}$; and annealing curve analysis at $98^{\circ} \mathrm{C}$ to $80^{\circ} \mathrm{C}$, ramping at $0.05^{\circ} \mathrm{C}$ per sec. The fluorescence curve was created using Microsoft Excel from raw fluorescence data obtained using the Genie Explorer version 2.0.6.3 software (Optigene). The results were based on the amplification curve for detecting positive or negative amplification, and the annealing curve for checking specific amplification with a single peak.

For LAMP assays with the QProbe, the reaction mixture described above also contained $1 \mu \mathrm{M}$ of the specific QProbe for P. nicotianae. The LAMP assay was performed as described above except that the annealing curve analysis was extended from $98^{\circ} \mathrm{C}$ to $40^{\circ} \mathrm{C}$ with ramping at $0.05^{\circ} \mathrm{C}$ per sec.

The specificity of the LAMP assay, with or without the QProbe, was assessed at least two times with each DNA sample. The sensitivity of the LAMP assay with or without the QProbe, and the average peak temperature of the QProbe, were determined in at least three experiments.

LAMP assay using the StepOnePlus system, with or without the QProbe. The LAMP reaction, with or without the QProbe, was also performed with the ABI StepOnePlus Real-Time PCR System. The reaction mixture was the same as that used with the GenieII system, except the concentration of the QProbe was $0.5 \mu \mathrm{M}$. First, short prerun $\left(70^{\circ} \mathrm{C}, 1 \mathrm{~min}\right)$ was carried out with empty plate to reduce the heating time for the main run. The main reaction was conducted with the following conditions: $68^{\circ} \mathrm{C}$ for $60 \mathrm{~min}(1 \mathrm{~min} \times 60$ cycles), followed by an annealing step with $98^{\circ} \mathrm{C}$ for $10 \mathrm{~s}$, then $80^{\circ} \mathrm{C}$ for $30 \mathrm{~s}$ (for QProbe: $45^{\circ} \mathrm{C}$ for $30 \mathrm{~s}$ ), then a melting step with gradual temperature increments of $0.3^{\circ} \mathrm{C} / \mathrm{s}$ to $98^{\circ} \mathrm{C}$ with "step and hold" detection, and finally $98^{\circ} \mathrm{C}$ for $10 \mathrm{~s}$. The fluorescence derivative data were collected during the melting phase. The assay was performed at least twice without the QProbe and at least twice with the QProbe.

\section{Results}

Design of genus-specific LAMP primers and $P$. nicotianaespecific QProbe. For the genus-specific detection of Phytophthora, we designed a LAMP primer set based on multiple alignments of the rDNA-ITS sequences from 27 species of Phytophthora (clades 1 to 10) (Abad et al. 2019), 11 species of Pythium (clades A to J) (Robideau et al. 2011), two species of Phytopythium, and one species of Halophytophthora (Supplementary Figure S1). The Pythium, Phytopythium, and Halophytophthora genera are closely related to Phytophthora (Robideau et al. 2011), and we included species from those genera in order to design primers that would be specific for Phytophthora. We also designed a $P$. nicotianae-specific quenching probe (QProbe) using the same multiple alignment (Supplementary Figure S1). The sequences of the primers and probe were based on the rDNA-ITS sequence (NCBI accession no. HQ643363) of $P$. nicotianae CBS 305.29 (Supplementary Figure S1 and Table 2).

Specificity of the LAMP assays, with and without the QProbe. Experiments to test the specificity and sensitivity of the LAMP primers and QProbe were performed using the GenieII system, which is a compact, lightweight instrument for performing real-time isothermal reactions with fluorescence measurement. This portable instrument has the advantage that it can be used in the field as well as the laboratory.

The specificity of the genus-specific LAMP primer set was assessed using mycelial DNA obtained from Phytophthora and closely related genera: 161 taxa (including subspecies, varieties, and hybrids) of Phytophthora, 12 species (12 isolates) of Pythium, 17 species (17 isolates) of Phytopythium, and one isolate each of the following soil-borne pathogens: Aphanomyces cochlioides, Fusaium oxysporum f. sp. fragariae, Plasmodiophora brassicae, Rhizoctonia solani, Saprolegnia parasitica, Sclerotinia sclerotiorum, and Verticillium albo-atrum (Table 1). Among the tested Phytophthora species, 159 taxa were detected within $60 \mathrm{~min}$, and most of these were detected within $30 \mathrm{~min}$, in duplicate assays. Two species, $P$. macrochlamydospora and $P$. insolita, were detected within

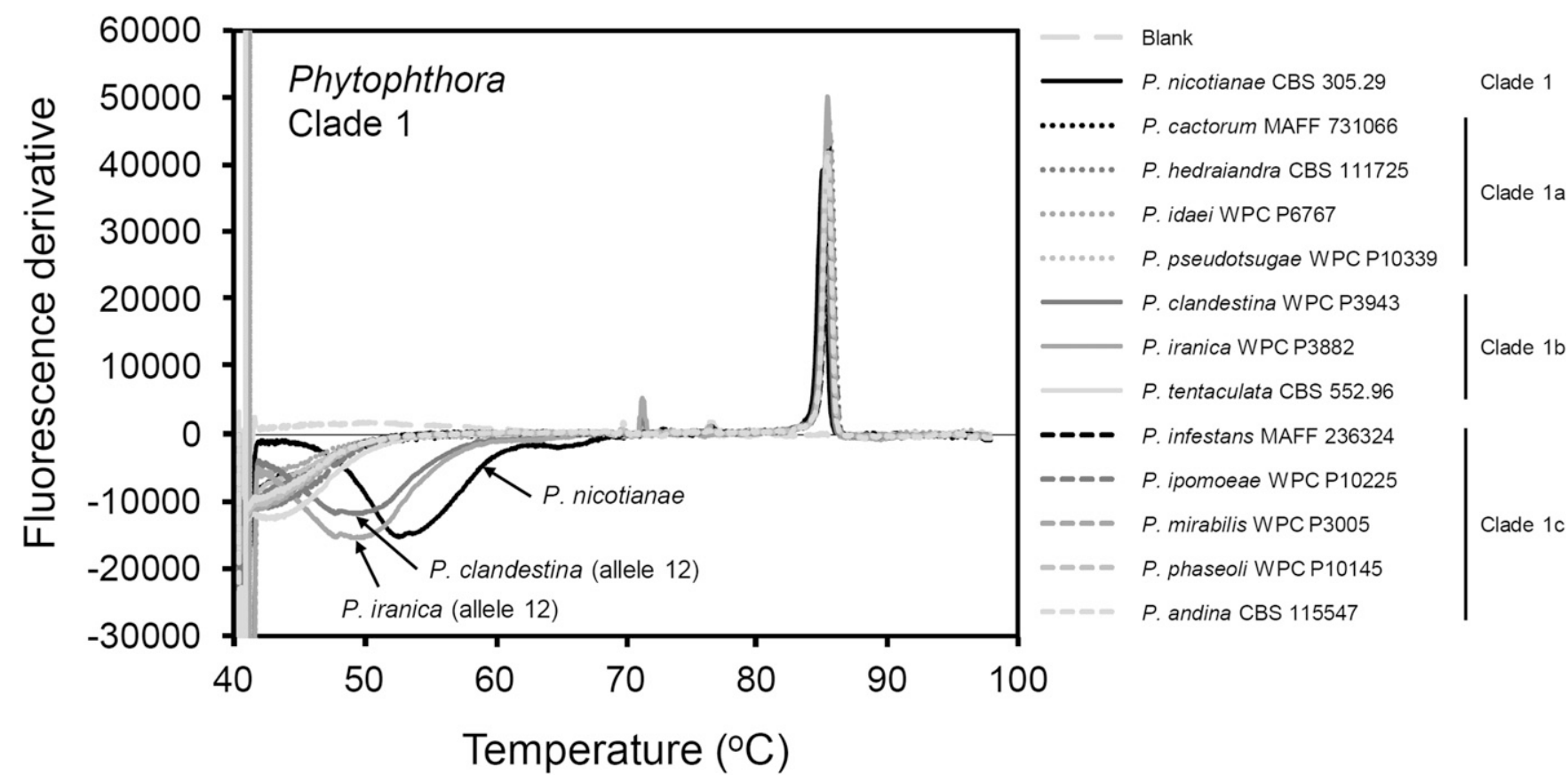

Fig. 1. Specificity of the Phytophthora genus-specific LAMP assay with the Phytophthora nicotianae-specific QProbe. Mycelial DNA samples were extracted from representative Phytophthora species in clade 1 . After amplification at $68^{\circ} \mathrm{C}$ for $60 \mathrm{~min}$, fluorescence derivative data during the annealing phase $\left(98\right.$ to $\left.40^{\circ} \mathrm{C}\right)$ were obtained. 
$60 \mathrm{~min}$ at least once in triplicate assays. No species were not detected at all (Table 1, first data column). Among the other genera, only two Phytopythium species, Pp. delawarense and Pp. fagopyri, were detected within $60 \mathrm{~min}$ at least once in triplicate assays (Table 1, first data column).
Next, we tested the specificity of $P$. nicotianae-QProbe by using fluorescence derivative data at the annealing phase of the detection assay for $P$. nicotianae. We determined that the optimum concentration of the QProbe was $1 \mu \mathrm{M}$, since this concentration showed a clear peak and was cost-effective (Supplementary Figure S2). The
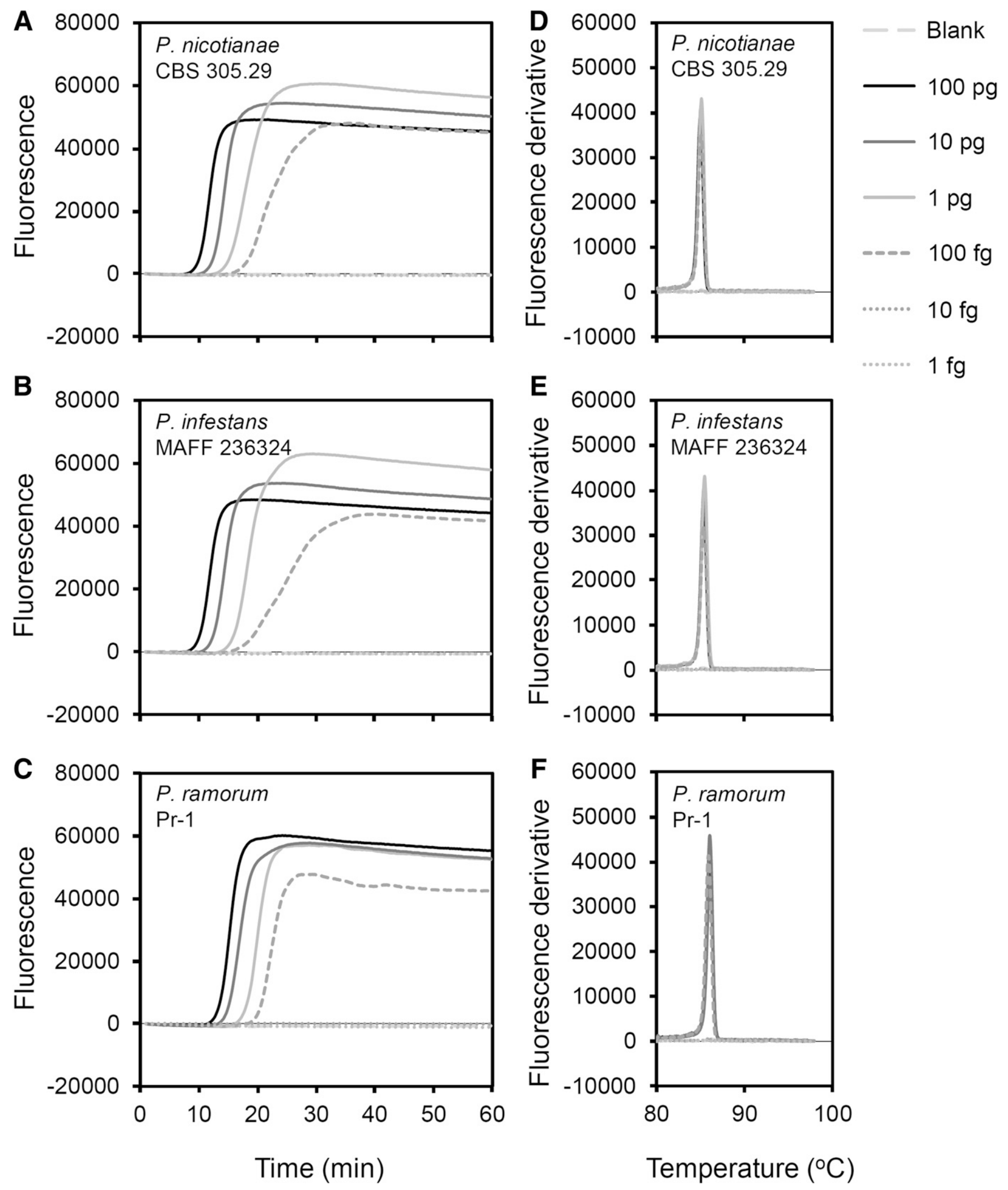

Fig. 2. Sensitivity of the Phytophthora genus-specific LAMP assay. Mycelial DNA from the Phytophthora species $P$. nicotianae CBS 305.29 (A and D), P. infestans MAFF 236324 ( $B$ and $\mathbf{E}$ ), and $P$. ramorum $\operatorname{Pr}-1$ (C and F) were serially diluted and subjected to LAMP assays. A-C, Amplification curves. D-F, After amplification at $68^{\circ} \mathrm{C}$ for 60 min, fluorescence derivative data during the annealing phase $\left(98\right.$ to $\left.80^{\circ} \mathrm{C}\right)$ were obtained. 
amplified target of the Phytophthora genus-specific primers was detected as a positive fluorescent peak at around $85^{\circ} \mathrm{C}$, and the correct target of the $P$. nicotianae-specific QProbe was detected as a negative fluorescent peak at $53.06 \pm 0.03^{\circ} \mathrm{C}$ (average $\pm \mathrm{SE}$, peak temperature of the original allele in Table 3 ). The stability of this negative peak temperature was confirmed using the $21 P$. nicotianae isolates listed in Table 1 (data not shown). We found 27 variations of the QProbe region among 175 Phytophthora taxa, and categorized them as "original" (i.e., the sequence for $P$. nicotianae CBS 305.29) and alleles 1 to 26 (see Tables 1 and 3). A representative species with each allele was then subjected to a genus-specific LAMP assay with the $P$. nicotianae-specific QProbe. We calculated the differences between the negative peak temperature of the correct target and other alleles to obtain delta temperature values (Table 3 ). The species with allele 12 (Phytophthora clandestina) had the smallest delta temperature value $\left(-4.22^{\circ} \mathrm{C}\right)$. All other alleles had negative peak temperatures that differed from that of the original allele by more than $10.9^{\circ} \mathrm{C}$ (Table 3). We then assayed 13 species from Phytophthora clade 1, including $P$. nicotianae and the two species carrying allele 12 (P. clandestina and P. iranica). As shown in Figure 1, the QProbe was able to distinguish $P$. nicotianae from all other species, including the two carrying allele 12. This result was confirmed in three experiments, with representative data shown in Figure 1.

To confirm the specificity of the QProbe, we assayed 29 species of Phytophthora (clades 1 to 10), 12 species of Pythium (clades A to J), one species of Phytopythium, and one isolate each of the seven other soil-borne pathogens. We used the genus-specific LAMP primers and the P. nicotianae-specific QProbe and tracked the fluorescence derivative data during the annealing phase. All the tested Phytophthora isolates were detected as positive peaks at around $85^{\circ} \mathrm{C}$

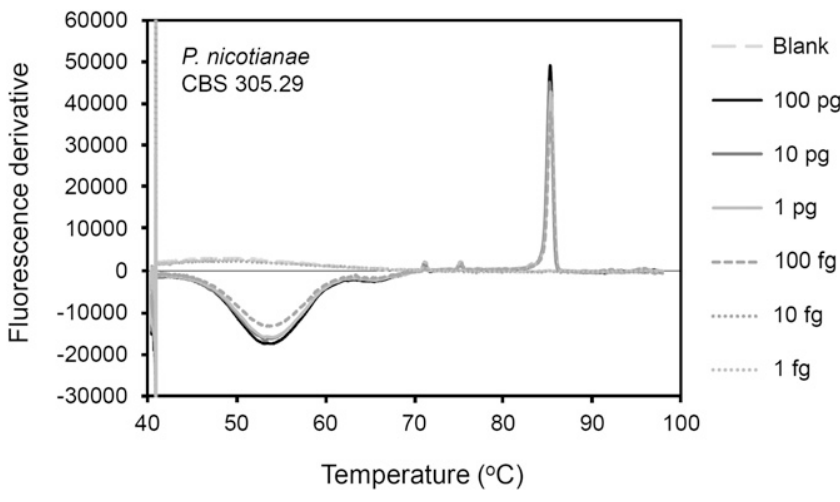

Fig. 3. Sensitivity of the Phytophthora genus-specific LAMP assay with the Phytophthora nicotianae-specific QProbe. Mycelial DNA from P. nicotianae CBS 305.29 was serially diluted and used for the assay. After amplification at $68^{\circ} \mathrm{C}$ for $60 \mathrm{~min}$, fluorescence derivative data during annealing phase $\left(98\right.$ to $40^{\circ} \mathrm{C}$ ) were obtained.
(Table 1, middle data column), while all 21 isolates of $P$. nicotianae, and no other isolates, were detected by the QProbe as negative peaks at around $53^{\circ} \mathrm{C}$ (Table 1 , third data column).

Sensitivity of LAMP assay with and without the QProbe. To test the detection limit of the Phytophthora genus-specific LAMP assay, we used serially diluted DNA samples (ranging from $1 \mathrm{fg}$ to 100 pg) from three representative species: $P$. nicotianae CBS 305.29 (clade 1), $P$. infestans MAFF 236324 (clade 1c), and P. ramorum Pr-1 (clade 8c). The detection limits for all three species were 100 $\mathrm{fg}$, and these limits were the same in each of at least five experiments per species; representative data are shown in Figure 2. Next, we tested the detection limit for $P$. nicotianae in LAMP assays with the QProbe. Serially diluted DNA samples of P. nicotianae were assayed, and the detection limit was found to be $100 \mathrm{fg}$ in 10 replicate experiments, with representative data shown in Figure 3.

Detection of Phytophthora spp. and $P$. nicotianae in inoculated and naturally infected plants. We tested the genus-specific LAMP assay with the $P$. nicotianae-specific QProbe in inoculated plants (tomato and eggplant) and naturally infected plants (periwinkle and tobacco). For these experiments, we extracted the DNA using the Kaneka Easy DNA Extraction Kit version 2, which we had previously determined was suitable for LAMP detection (Hieno et al. 2019). The LAMP assays, performed using the GenieII system with the Phytophthora genus-specific primers, amplified the target DNA in all samples within $30 \mathrm{~min}$ (Table 4, first data column). There was no amplification by LAMP assay with DNA extracted from healthy plant tissues (data not shown). When the LAMP assay was performed with the QProbe, all samples showed positive fluorescent peaks at around $85^{\circ} \mathrm{C}$ (Table 4 , middle data column). Samples from plants infected with $P$. nicotianae also showed negative fluorescent peaks at around $53^{\circ} \mathrm{C}$ (Table 4, last data column). We also confirmed that there was no amplification from healthy plants in LAMP assays with the QProbe (data not shown). These results were confirmed in at least three experiments, and representative data are shown in Figure 4.

Application of the LAMP assay, with and without the QProbe, using an alternative real-time fluorometer. The GenieII system is versatile and portable, but it has the disadvantage that it can process no more than 16 samples at one time. Therefore, we applied the LAMP assay, with or without the QProbe to the ABI StepOnePlus Real-Time PCR System, which has the capacity for 96 samples. For this system we substituted a melting curve analysis for the annealing curve analysis (see Materials and Methods). First, we tested the optimal concentration of the QProbe and found it to be $0.5 \mu \mathrm{M}$, which is half of the optimal concentration of the GenieII system (Supplementary Figure S3). When a higher concentration, free QProbe was detected as non-negligible noise, although it did not interfere with the LAMP assay. Next, we checked the specificity of the assay using mycelial DNA from representative Phytophthora, Pythium, and Phytopythium species (* in Table 1) and DNA from infected plants (* in Table 4$)$. There were no differences in the results between the GenieII and StepOnePlus systems. However, in the

Table 4. Results of assays of inoculated and naturally infected plants using the LAMP assay with or without the QProbe

\begin{tabular}{|c|c|c|c|c|c|c|c|c|}
\hline Sample & Host & Tissue & $\begin{array}{l}\text { Phytophthora } \\
\text { species }\end{array}$ & Isolate & Location & $\begin{array}{c}\text { Detection of } \\
\text { genus by LAMPa }\end{array}$ & $\begin{array}{l}\text { Detection of genus by } \\
\text { LAMP with QProbe }\end{array}$ & $\begin{array}{c}\text { Detection of } P \text {. } \\
\text { nicotianae by LAMP } \\
\text { with QProbe }^{\mathrm{a}}\end{array}$ \\
\hline \multirow{4}{*}{$\begin{array}{l}\text { Inoculated } \\
\text { plants }\end{array}$} & Tomato & Fruit & P. capsici & CH01CUCU10 & - & + & $+*$ & $-^{*}$ \\
\hline & & & P. nicotianae & GK10Eg1 & - & + & $+*$ & $+^{*}$ \\
\hline & Eggplant & Fruit & P. capsici & CH01CUCU10 & - & + & $+^{*}$ & $-*$ \\
\hline & & & P. nicotianae & GK10Eg1 & - & + & $+^{*}$ & $+*$ \\
\hline \multirow{2}{*}{$\begin{array}{l}\text { Natural } \\
\text { infected } \\
\text { plants }\end{array}$} & Periwinkle & Stem & P. nicotianae & - & Gifu, Japan & + & $+^{*}$ & $+^{*}$ \\
\hline & Tobacco & Stem & P. nicotianae & - & $\begin{array}{r}\text { Java island, } \\
\text { Indonesia }\end{array}$ & + & $+^{*}$ & $+^{*}$ \\
\hline
\end{tabular}

\footnotetext{
${ }^{a}$ At least two repeats were performed. +, detected within $60 \mathrm{~min} ;-$, , not detected within $60 \mathrm{~min}$. Asterisks indicate samples that were tested and confirmed using
} the ABI StepOnePlus Real-Time PCR System. 
StepOnePlus system, the negative peak temperature for the QProbe with $P$. nicotianae DNA was shifted slightly $\left(+2^{\circ} \mathrm{C}\right)$ from ca. $53^{\circ} \mathrm{C}$ (Table 3) to ca. $55^{\circ} \mathrm{C}$ (Supplementary Figure S3). We also used the StepOnePlus system to perform the same experiments in Figures 2 and 3, to check the sensitivity of the LAMP assay with and without the QProbe and found no differences from the results obtained with the GenieII system (data not shown).

\section{Discussion}

We designed a Phytophthora genus-specific LAMP primer set based on 27 species in phylogenetic clades 1 to 10 (Abad et al. 2019), and this primer set was able to detect all 161 of the tested Phytophthora taxa (including subspecies, varieties, and hybrids) (Table 1). The number of species tested in this study is greater than the numbers tested in previous studies with PCR primers: 101 species (Bilodeau et al. 2014), 45 species (Scibetta et al. 2012), 35 species
(Schena et al. 2008), and RPA primers: 136 taxa (Miles et al 2015). Based on these numbers, our LAMP primer set should be the most reliable for the specific detection of Phytophthora spp. However, among the closely related genera that we tested, $P p$. delawarense and Pp. fagopyri also gave positive results in our assays (Table 1), although the detection time for $100 \mathrm{pg}$ of mycelial DNA from these species was 40 or more minutes (data not shown). These species are not common, and only one host has been reported for each of them (USDA Agricultural Research Service, https://nt.ars-grin. gov/fungaldatabases/fungushost/fungushost.cfm). Therefore, we feel that our primer set will be useful for the specific detection of Phytophthora spp. in a quarantine setting.

There have only been a few studies on QProbes or QPrimer methods in LAMP assays. Most have been designed for the detection of clinical viruses, such as the real-time reverse transcription LAMP assay with a QProbe for the Middle East respiratory syndrome
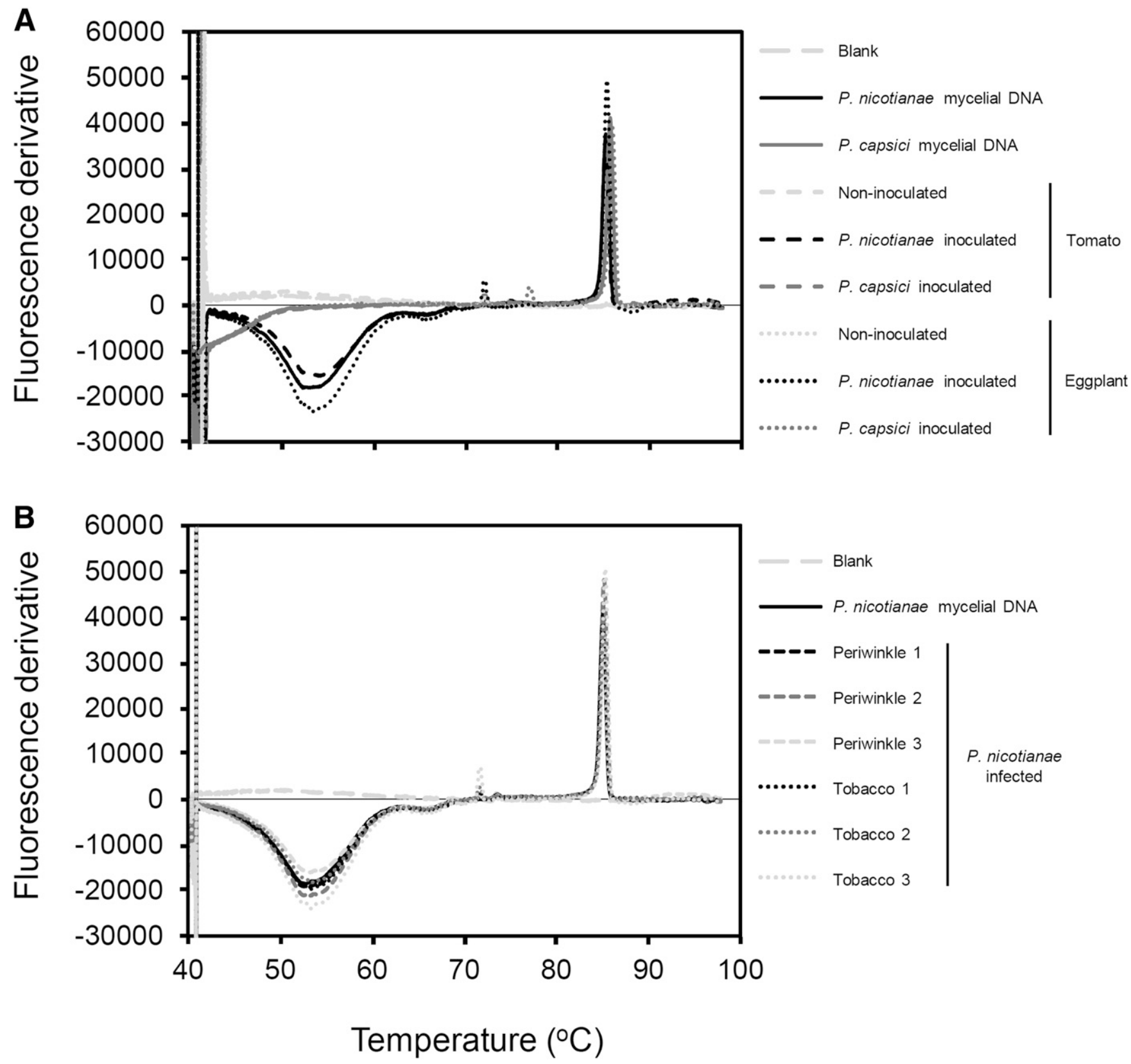

Fig. 4. Detection from inoculated and naturally infected plants by the LAMP assay with the QProbe. Non-inoculated and inoculated fruits (A) and naturally infected plants (B) were subjected to the Phytophthora genus-specific LAMP assay with the Phytophthora nicotianae-specific QProbe. After amplification at $68^{\circ} \mathrm{C}$ for 60 min, fluorescence derivative data during the annealing phase $\left(98\right.$ to $\left.40^{\circ} \mathrm{C}\right)$ were obtained. A reaction mixture without DNA (Blank) was used as a negative control, and $P$. nicotianae mycelial DNA was used as a positive control. A, Tomato and eggplant fruits inoculated with P. nicotianae GK10Eg1 or P. capsici CH01CUCU10. Mycelial DNA from P. capsici was used as an additional negative control. B, Periwinkle and tobacco stems naturally infected with $P$. nicotianae. 
coronavirus (Shirato et al. 2018), or the real-time reversetranscription LAMP assay with a QPrimer for the influenza virus and the respiratory syncytial virus (Takayama et al. 2019). Among plant pathogens, a universal QProbe system was established for distinguishing races of Fusarium oxysporum f. sp. lycopersici (Ayukawa et al. 2017). This study is the second report on using a QProbe in a LAMP-based detection assay for a plant pathogenic microorganism.

$P$. nicotianae is a species with a broad host range and worldwide distribution, and it probably has a large amount of genetic variation (Afandi et al. 2019). Therefore, we confirmed the conservation of the P. nicotianae-specific QProbe sequence (Supplementary Figure S1, Table 2) using 100 rDNA-ITS sequences downloaded from the NCBI database (https://www.ncbi.nlm.nih.gov/nucleotide/). The LAMP assay with the $P$. nicotianae-specific QProbe was able to distinguish $P$. nicotianae from other tested Phytophthora taxa, which all had at least one sequence mismatch in the QProbe region (Fig. 1, Table 3). This high level of specificity was also found in the previous study on the specific detection of $F$. oxysporum f. sp. lycopersici races with single nucleotide variations (Ayukawa et al. 2017). It should be noted that the concentration of the QProbe affected the negative peak temperature: higher concentrations gave higher negative peak temperatures (Supplementary Figure S2).

Our method for the simultaneous detection of Phytophthora spp. and $P$. nicotianae is highly cost-effective when compared with separate assays using genus-specific primers (this study) and $P$. nicotianae species-specific primers (Hieno et al. 2019). The cost for reagents is about $20 \%$ lower for simultaneous detection than for separate assays, and there are significant savings in time and labor as well.

In this study, we developed the simultaneous detection method using the lightweight and portable GenieII system, and then confirmed that the method can also be used with a larger instrument, the ABI StepOnePlus Real-Time PCR System. The StepOnePlus system has the capacity for 96 samples; however, we found that nonspecific amplification occurred if we did not add a preheating step to the procedure (data not shown; see Materials and Methods).

As mentioned previously, several other molecular detection methods have been developed for the Phytophthora genus or for certain species within the genus. Schena et al. (2008) developed a PCRbased detection method for the genus and 15 species. Detection by PCR is a very popular approach, and it has the advantage that its products can be sequenced. On the other hand, PCR assays require long reaction times and the products are often detected using timeconsuming gel electrophoresis. Miles et al. (2015) developed two multiplex RPA assays with fluorescent probes for detecting either the genus (with an internal plant control) or two species: $P$. ramorum and $P$. kernoviae. Like LAMP assays, RPA is an isothermal amplification method with a short reaction time, and the results are available immediately when using a real-time fluorometer. The use of the internal control provides the advantage of eliminating false negative results; however, the RPA-based detection method of Miles et al. (2015) requires two assays for detecting the genus and the individual Phytophthora species. Bilodeau et al. (2014) developed a multiplex real-time PCR method with TaqMan probes for detecting the genus, 13 species, and one species complex, and this method also includes an internal plant control. Both RPA- and TaqMan-based detection methods use fluorescent probes and are less likely to show nonspecific amplification than the LAMP method, which uses a doublestranded DNA-binding fluorescent dye. However, we have found that nonspecific amplification can be avoided if the reaction is started within 5 min after adding the template DNA. The detection method that we have developed, based on the LAMP assay with a QProbe, has the advantages of simultaneous detection in a single, rapid reaction, and immediate detection using a portable instrument. Portable real-time fluorometers for LAMP such as the GenieII are generally cheaper than real-time PCR systems.

In our previous study (Hieno et al. 2019), we designed a P. nicotianae species-specific LAMP primer and compared three methods for extracting DNA from diseased plants. We selected the Kaneka
Easy DNA Extraction Kit version 2 for future use because it was rapid (30 min needed for sampling and extraction) and the DNA was stable for use in LAMP assays and storable for around 2 years at $4^{\circ} \mathrm{C}$. This study confirmed that the DNA extraction kit was applicable not only for LAMP assays, but also for LAMP assays with QProbes. The total detection time from sampling to results was around $120 \mathrm{~min}$. Therefore, we have developed an effective, timesaving method for the simultaneous detection of all Phytophthora genus members and P. nicotianae specifically. Fichtner et al. (2012) identified symptomless $P$. kernoviae infections in North American native plants. Our detection method can be used in on-site quarantine inspections and will be effective for identifying Phytophthora even in asymptomatic imported plants.

\section{Acknowledgments}

We thank Emeritus Prof. E. M. Hansen, Prof. M. D. Coffey, Dr. P. W. Tooley, Prof. C. Hong, Dr. B. S. Weir, Dr. T. I. Burgess, Dr. T. Jung, Mr. S. Uematsu, and Dr. H. Watanabe for providing isolates of many important Phytophthora spp., and Dr. S. Subandiyah and Dr. A. Wibowo for providing plant DNA samples.

\section{Literature Cited}

Abad, Z. G., Burgess, T., Bienapfl, J. C., Redford, A. J., Coffey, M., and Knight, L. 2019. IDphy: Molecular and morphological identification of Phytophthora based on the types. USDA APHIS PPQ S\&T Beltsville Lab, USDA APHIS PPQ S\&T ITP, Centre for Phytophthora Science and Management, and World Phytophthora Collection. https://idtools.org/id/phytophthora/index.php (accessed November 2019)

Afandi, A., Hieno, A., Wibowo, A., Subandiyah, S., Afandi, Suga, H., Tsuchida, K., and Kageyama, K. 2019. Genetic diversity of Phytophthora nicotianae reveals pathogen transmission mode in Japan. J. Gen. Plant Pathol. 85:189-200.

Ayukawa, Y., Hanyuda, S., Fujita, N., Komatsu, K., and Arie, T. 2017. Novel loop-mediated isothermal amplification (LAMP) assay with a universal QProbe can detect SNPs determining races in plant pathogenic fungi. Sci. Rep. 7:4253.

Bilodeau, G. J., Martin, F. N., Coffey, M. D., and Blomquist, C. L. 2014 Development of a multiplex assay for genus- and species-specific detection of Phytophthora based on differences in mitochondrial gene order. Phytopathology 104:733-748.

Brasier, C. 2009. Phytophthora biodiversity: How many Phytophthora species are there? Pages 101-115 in: Proceedings of the Fourth Meeting of the International Union of Forest Research Organizations (IUFRO) Working Party S07.02.09: Phytophthoras in Forests and Natural Ecosystems. E. M. Goheen and S. J. Frankel, tech. coords. U.S. Department of Agriculture Forest Service, Pacific Southwest Research Station, Albany, CA. https://www.fs.fed.us/psw/ publications/documents/psw_gtr221/psw_gtr221.pdf

Brasier, C. M., Beales, P. A., Kirk, S. A., Denman, S., and Rose, J. 2005. Phytophthora kernoviae sp. nov., an invasive pathogen causing bleeding stem lesions on forest trees and foliar necrosis of ornamentals in the UK. Mycol. Res. 109:853-859.

de Bary, A. 1876. Researches into the nature of the potato fungus, Phytophthora infestans. Roy. Agr. Soc. England J. Ser. 2 12:239-269.

Drake, B., and Jones, G. 2017. Public value at risk from Phytophthora ramorum and Phytophthora kernoviae spread in England and Wales. J. Environ. Manage. 191:136-144.

Fichtner, E. J., Rizzo, D. M., Kirk, S. A., and Webber, J. F. 2012. Infectivity and sporulation potential of Phytophthora kernoviae to select North American native plants. Plant Pathol. 61:224-233.

Garkaklis, M. J., Calver, M. C., Wilson, B. A., and Hardy, G. E. S. J. 2004. Habitat alteration caused by an introduced plant disease, Phytophthora cinnamomi: a potential threat to the conservation of Australian forest fauna. Pages 899-913 in: Conservation of Australia's Forest Fauna. D. Lunney, ed. Royal Zoological Society of New South Wales, Mosman, NSW, Australia.

Goss, E. M., Carbone, I., and Grünwald, N. J. 2009. Ancient isolation and independent evolution of the three clonal lineages of the exotic sudden oak death pathogen Phytophthora ramorum. Mol. Ecol. 18:1161-1174.

Goss, E. M., Larsen, M., Vercauteren, A., Werres, S., Heungens, K., and Grünwald, N. J. 2011. Phytophthora ramorum in Canada: evidence for migration within North America and from Europe. Phytopathology 101:166-171.

Goss, E. M., Tabima, J. F., Cooke, D. E., Restrepo, S., Fry, W. E., Forbes, G. A., Fieland, V. J., Cardenas, M., and Grünwald, N. J. 2014. The Irish potato famine pathogen Phytophthora infestans originated in central Mexico rather than the Andes. Proc. Natl. Acad. Sci. USA 111:8791-8796.

Grünwald, N. J., Goss, E. M., and Press, C. M. 2008. Phytophthora ramorum: a pathogen with a remarkably wide host range causing sudden oak death on oaks and ramorum blight on woody ornamentals. Mol. Plant Pathol. 9:729-740.

Guenthner, J. F., Michael, K. C., and Nolte, P. 2001. The economic impact of potato late blight on US growers. Potato Res. 44:121-125.

Hansen, E. M. 2015. Phytophthora species emerging as pathogens of forest trees Curr. For. Rep. 1:16-24. 
Haverkort, A. J., Boonekamp, P. M., Hutten, R., Jacobsen, E., Lotz, L. A. P., Kessel, G. J. T., Visser, R. G. F., and Vossen, E. A. G. 2008. Societal costs of late blight in potato and prospects of durable resistance through cisgenic modification. Potato Res. 51:47-57.

Hieno, A., Li, M., Afandi, A., Otsubo, K., Suga, H., and Kageyama, K. 2019. Rapid detection of Phytophthora nicotianae by simple DNA extraction and real-time loop-mediated isothermal amplification assay. J. Phytopathol. 167:174-184.

Kaneko, H., Kawana, T., Fukushima, E., and Suzutani, T. 2007. Tolerance of loopmediated isothermal amplification to a culture medium and biological substances. J. Biochem. Biophys. Methods 70:499-501.

Kurata, S., Kanagawa, T., Yamada, K., Torimura, M., Yokomaku, T., Kamagata, Y., and Kurane, R. 2001. Fluorescent quenching-based quantitative detection of specific DNA RNA using a BODIPY ${ }^{\circledR}$ FL-labeled probe or primer. Nucleic Acids Res. 29:e34.

Martin, F. N., Tooley, P. W., and Blomquist, C. L. 2004. Molecular detection of Phytophthora ramorum, the causal agent of sudden oak death in California, and two additional species commonly recovered from diseased plant material. Phytopathology 94:621-631.

Miles, T. D., Martin, F. N., and Coffey, M. D. 2015. Development of rapid isothermal amplification assays for detection of Phytophthora spp. in plant tissue. Phytopathology 105:265-278.

Mori, Y., Nagamine, K., Tomita, N., and Notomi, T. 2001. Detection of loopmediated isothermal amplification reaction by turbidity derived from magnesium pyrophosphate formation. Biochem. Biophys. Res. Commun. 289:150-154.

Mori, Y., and Notomi, T. 2009. Loop-mediated isothermal amplification (LAMP): a rapid, accurate, and cost-effective diagnostic method for infectious diseases. J. Infect. Chemother. 15:62-69.

Nagamine, K., Hase, T., and Notomi, T. 2002. Accelerated reaction by loop-mediated isothermal amplification using loop primers. Mol. Cell. Probes 16:223-229.

Notomi, T., Okayama, H., Masubuchi, H., Yonekawa, T., Watanabe, K., Amino, N., and Hase, T. 2000. Loop-mediated isothermal amplification of DNA. Nucleic Acids Res. 28:e63.

Rands, R. D., 1922. Streepkanker van Kaneel, veroorzaakt door Phytophthora cinnamomi $\mathrm{n}$. sp. Mededeelingen van het Instituut voor plantenziekten 54:1-54.

Robideau, G. P., De Cock, A. W., Coffey, M. D., Voglmayr, H., Brouwer, H., Bala, K., Chitty, D. W., Désaulniers, N., Eggertson, Q. A., Gachon, C. M., Hu, C. H.,
Küpper, F. C., Rintoul, T. L., Sarhan, E., Verstappen, E. C., Zhang, Y., Bonants, P. J., Ristaino, J. B., and Lévesque, C. A. 2011. DNA barcoding of oomycetes with cytochrome $c$ oxidase subunit I and internal transcribed spacer. Mol. Ecol. Resour. 11:1002-1011.

Sakoda, T., Goto, H., Kanno, T., Hiyama, T., Hirakawa, T., Nakanishi, Y., and Hirata, T. 2017. Ramorum Blight of Rhododendron sp. Caused by Phytophthora ramorum Intercepted in Plant Quarantine Inspection in Japan. Res. Bull. Plant Prot. Serv. Jpn. 53:75-81.

Schena, L., Duncan, J. M., and Cooke, D. E. L. 2008. Development and application of a PCR-based molecular tool box for the identification of Phytophthora species damaging forests and natural ecosystems. Plant Pathol. 57:64-75.

Schena, L., Hughes, K. J., and Cooke, D. E. 2006. Detection and quantification of Phytophthora ramorum, $P$. kernoviae, $P$. citricola and $P$. quercina in symptomatic leaves by multiplex real-time PCR. Mol. Plant Pathol. 7:365-379.

Scibetta, S., Schena, L., Chimento, A., Cacciola, S. O., and Cooke, D. E. 2012. A molecular method to assess Phytophthora diversity in environmental samples. J. Microbiol. Methods 88:356-368.

Shirato, K., Semba, S., El-Kafrawy, S. A., Hassan, A. M., Tolah, A. M., Takayama, I., Kageyama, T., Notomi, T., Kamitani, W., Matsuyama, S., and Azhar, E. I. 2018. Development of fluorescent reverse transcription loop-mediated isothermal amplification (RT-LAMP) using quenching probes for the detection of the Middle East respiratory syndrome coronavirus. J. Virol. Methods 258:41-48.

Takayama, I., Nakauchi, M., Takahashi, H., Oba, K., Semba, S., Kaida, A., Kubo, H., Saito, S., Nagata, S., Odagiri, T., and Kageyama, T. 2019. Development of real-time fluorescent reverse transcription loop-mediated isothermal amplification assay with quenching primer for influenza virus and respiratory syncytial virus. J. Virol. Methods 267:53-58.

Van Poucke, K., Franceschini, S., Webber, J. F., Vercauteren, A., Turner, J. A. McCracken, A. R., Heungens, K., and Brasier, C. M. 2012. Discovery of a fourth evolutionary lineage of Phytophthora ramorum: EU2. Fungal Biol. 116:1178-1191.

Werres, S., Marwitz, R., Man In't veld, W. A., De Cock, A. W. A. M., Bonants, P. J. M., De Weerdt, M., Themann, K., Ilieva, E., and Baayen, R. P. 2001 Phytophthora ramorum sp. nov., a new pathogen on Rhododendron and Viburnum. Mycol. Res. 105:1155-1165. 